\title{
The Circulatory Effects of Nifedipine in the Conscious Newborn Lamb
}

\author{
J. Y. COE, D. LOUNDES, F. COCEANI, AND P. M. OLLEY \\ Cardiovascular Research Focus and Neurosciences Division, Department of Pediatrics, The Hospital for Sick \\ Children, Toronto, Ontario, Canada
}

\begin{abstract}
The cardiac, pulmonary vascular, and systemic vascular effects of bolus injections $(2.5,25,50 \mu \mathrm{g}$ / $\mathrm{kg}$ ) and 5-min infusions of $50 \mu \mathrm{g} / \mathrm{kg} / \mathrm{min}$ of Nifedipine were tested in conscious, chronically instrumented newborn lambs. While breathing room air, bolus injections of 50 $\mu \mathrm{g} / \mathrm{kg}$ into the pulmonary artery caused the cardiac index and left ventricular dp/dt to fall as did systemic arterial pressure and calculated resistance (all changes significant $p<0.05$ ). Pulmonary artery, pulmonary vein, and left atrial pressure all tended to increase and there was a shift in low away from the injected lung $(14 \pm 0.05 \%)$. Pulmo$n: y$ arteriolar resistance in the injected lung increased significantly $(p<0.05)$. Nifedipine failed to prevent hypoxia-induced pulmonary vasoconstriction, and when given during hypoxia, caused a further rise in pulmonary artery pressure with a marked fall in left ventricular dp/dt and systemic vascular resistance. These acute effects peaked $30 \mathrm{~s}$ to $2 \mathrm{~min}$ after injection and all hemodynamic variables returned to baseline by $10 \mathrm{~min}$. Five-min infusions caused similar effects which completely reversed 20 min after the infusion was stopped. Nifedipine causes significant cardiac depression combined with systemic vasodilatation and pulmonary arteriolar constriction in conscious newborn lambs. Assuming similar actions in humans, it seems quite unsuitable for the therapy of pulmonary hypertensive problems of newborn infants. (Pediatr Res 20: 1-4, 1986)
\end{abstract}

Neonatal pulmonary hypertension, which may complicate meconium aspiration, septicemia, respiratory distress syndrome, or be "idiopathic" continues to be difficult to treat because of the lack of a specific pulmonary vasodilator.

A relatively new class of drugs, the calcium channel blockers have been used to treat pulmonary hypertension in adults (1-3). Among these drugs, Nifedipine, a dihydropyridine derivative, is a powerful peripheral vasodilator which acts independently of heart rate, and in adults has a less cardiodepressant action than either Verapamil or Diltiazem (4). Furthermore it acutely dilates pulmonary vessels constricted by hypoxia in adult patients with acute respiratory distress (3).

Assuming that Nifedipine could be of potential use to treat pulmonary hypertension in the newborn we have studied its effects in conscious chronically instrumented newborn lambs.

\section{METHODS}

Twelve newborn lambs, mean age 4 days (range 2-7) and mean weight $4.6 \mathrm{~kg}$ (range 3.6-5.6), were operated on under

Received April 3, 1985; accepted August 12, 1985.

Reprint requests P. M. Olley, Cardiovascular Research, The Hospital for Sick Children, 555 University Avenue, Toronto, Ontario, Canada M5G 1X8.

This work was supported by the Ontario Heart Foundation. J.Y.C. is a Research Fellow of the Canadian Heart Foundation. general anesthesia. Through a left thoracotomy, electromagnetic flow probes ( $\mathrm{C}$ and $\mathrm{C}$ Instruments, Culver City, $\mathrm{CA}$ ) were placed around the left and right pulmonary arteries and fine polyethylene catheters introduced into a right pulmonary vein and the left atrium through purse string sutures in the left atrial wall. The probe connectors and catheters were tunneled subcutaneously to a dorsal pouch between the scapulae and the chest was closed. Initial drug studies were performed at a mean age of $7 \pm 2$ days. Under light anesthesia (oxygen 4 liter/min, nitrous oxide 4 liter/ min, halothane $<0.5 \%$ ) indwelling sheaths were placed in the right carotid artery and both external jugular veins, permitting the repeated introduction of catheters, without further anesthetic, over a period of $1-2 \mathrm{wk}$. Using these sheaths, catheters were introduced into the right pulmonary artery (with its tip just distal to the flow probe) right atrium and aortic root. In all animals, a high fidelity Millar catheter was placed in the left ventricle.

For introduction of the catheters and subsequent drug studies the lamb was placed in a wooden frame with gentle restraint. Studies were performed with the lamb breathing spontaneously, either room air or a mixture of approximately $12 \%$ oxygen, $5 \%$ carbon dioxide in nitrogen. In the latter case a large plastic hood was placed over the whole animal and ambient air replaced by the gas mixture with the flow rate adjusted so that arterial $\mathrm{PO}_{2}$ fell to 49 Torr or less over $15 \mathrm{~min}$. Oxygen percentage was checked using an Critikon oxygen meter.

All animal procedures were approved by the Animal Care Committee of the Hospital.

Details of flow probe measurements and their validation have been previously published from our laboratories (5). Flows were measured using Gould 2202 flow meters. Cardiac output was obtained by summing the right and left pulmonary blood flows. Pressures were continuously monitored from both atria, the right pulmonary vein, and the aorta, using Statham P23Db transducers and an Electronics for Medicine DR8 recorder. The high fidelity left ventricular pressure was differentiated (Millar Transducer Control unit, model TCB 100) to provide peak positive left ventricular $\mathrm{dp} / \mathrm{dt}$. Arterial blood gases were checked periodically through each study and lines were kept patent by flushing with small volumes of heparinized saline $(4 \mathrm{U} / \mathrm{ml})$.

Drug preparation. Nifedipine (Miles Laboratories, Rexdale, Ontario, Canada) was diluted in a vehicle consisting of $150 \mathrm{~g}$ polyethylene glycol $400,150 \mathrm{~g}$ of $96 \%$ ethanol, made up to 1 liter with sterile water. The drug was administered as either a bolus into the right pulmonary artery in doses of $2.5,25$, and 50 $\mu \mathrm{g} / \mathrm{kg}(0.3-1.5 \mathrm{ml})$ or continuously infused at $50 \mu \mathrm{g} / \mathrm{kg} / \mathrm{min}(1.5$ $\mathrm{ml} / \mathrm{min}$ ) for $5 \mathrm{~min}$. Doses greater than $50 \mu \mathrm{g} / \mathrm{kg}$ were not tolerated because of severe hypotension and cardiac depression. Vehicle alone was also tested as bolus injections. Thirty minutes were allowed to elapse between tests and precautions were taken to avoid exposure of the drug to light.

All three doses of Nifedipine were tested as a bolus injection in six animals during normoxia, and at the $50 \mu \mathrm{g} / \mathrm{kg}$ dose in three animals during hypoxia. In five experiments the response to hypoxia was tested after the lamb had received three successive 
doses of Nifedipine, $2.5,25$, and $50 \mu \mathrm{g} / \mathrm{kg}$ to a total of $77.5 \mu \mathrm{g} /$ $\mathrm{kg}$. Nifedipine was infused in three animals. Finally, three lambs were given a bolus of $50 \mu \mathrm{g} / \mathrm{kg}$ into the aortic root.

Systemic vascular resistance was calculated by dividing cardiac index into the difference between mean aortic and mean right atrial pressure. Pulmonary arteriolar resistance in the injected lung was obtained by dividing the difference between mean pulmonary artery and mean pulmonary vein pressures by the flow. Both are expressed in $\mathrm{U} / \mathrm{kg}$.

A paired or unpaired Student's $t$ test was used to compare responses at a given time to baseline. Multiple time samples of each variable were subjected to an analysis of variance to determine if the response was significant. The significance figures in the text for each response are the ANOVA results.

\section{RESULTS}

Vehicle alone, which is a hypoosmolar solution, caused no significant change in cardiac index or left ventricular dp/dt (Fig. 1). Pulmonary artery pressure and resistance rose slightly $(p<$ 0.05 at $30 \mathrm{~s}$ ), while systemic pressure and resistance also increased but not significantly (Figs. 2 to 4 ).

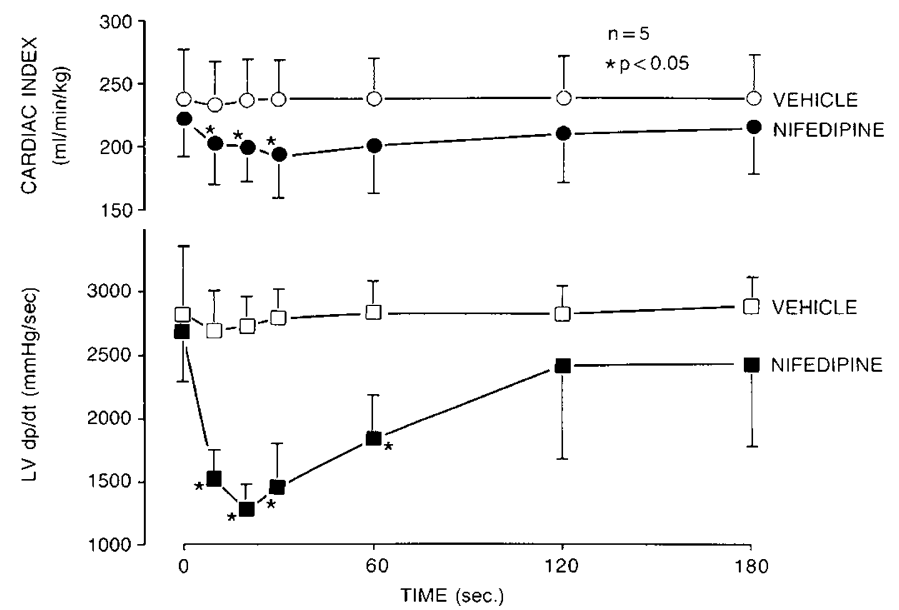

Fig. 1. Bolus injections of vehicle $(1.5 \mathrm{ml})$ or Nifedipine $50 \mu \mathrm{g} / \mathrm{kg}$ into the right pulmonary artery $(R P A)$. Effect on cardiac index and left ventricular $(L V)$ contractility. ${ }^{*}$ Significantly different from baseline.

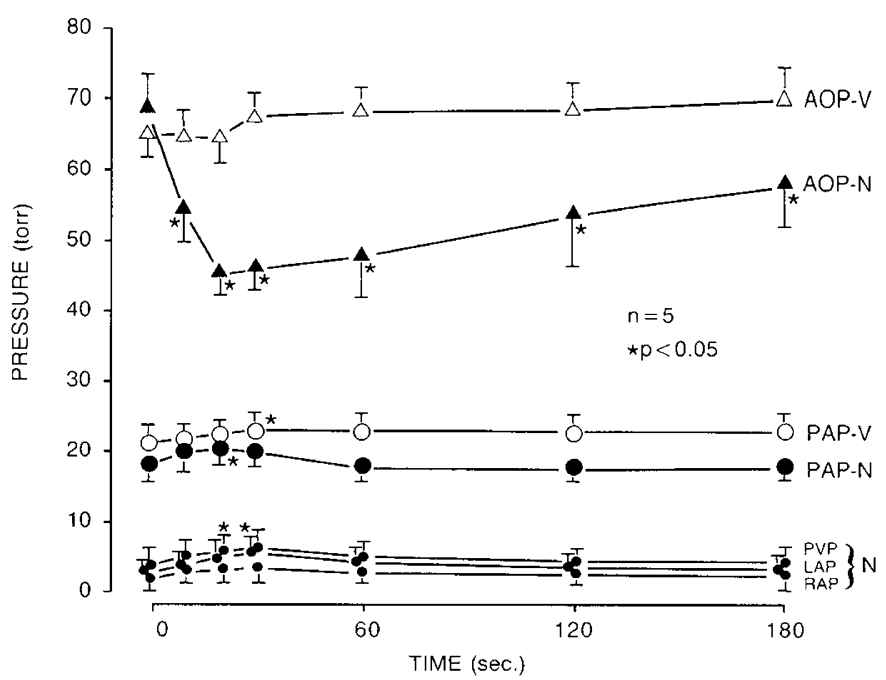

Fig. 2. Effect of bolus injections of vehicle $(V)$ or $50 \mu \mathrm{g} / \mathrm{kg}$ of Nifedipine $(N)$ into the right pulmonary artery $(R P A)$ on aortic pressure $(A O P)$, pulmonary artery pressure $(P A P)$, right pulmonary vein pressure $(P V P)$, left atrial pressure ( $L A P)$, and $R A P$.

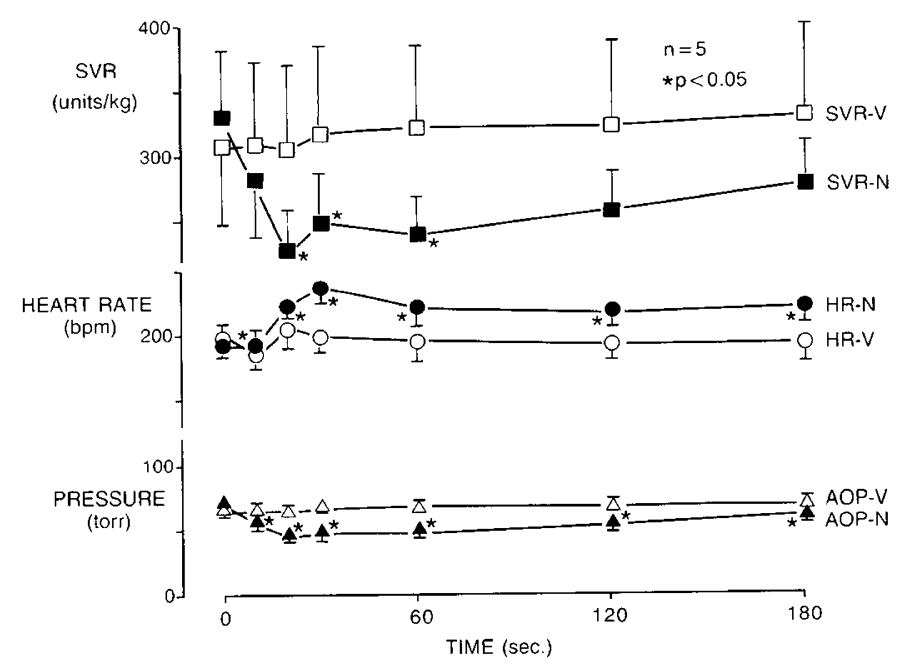

Fig. 3. Systemic vascular changes after intrapulmonary bolus injections of vehicle and Nifedipine. Same volume and dose as previous figures. $S V R$, systemic vascular resistance; $H R$, heart rate. Other abbreviations as in legend for Figure 2.

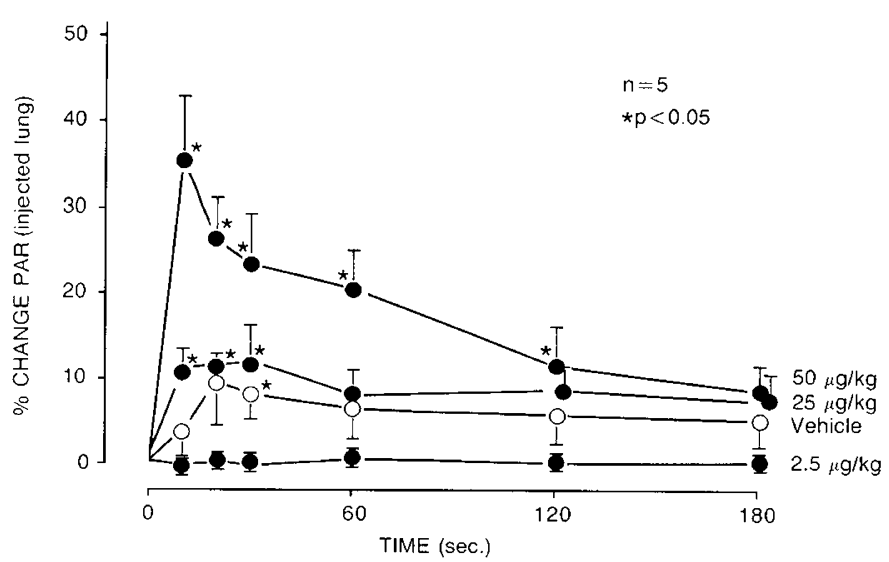

Fig. 4. Effects of vehicle and three different doses of Nifedipine on pulmonary arteriolar resistance $(P A R)$.

Nifedipine bolus injections during normoxia. Nifedipine 2.5 $\mu \mathrm{g} / \mathrm{kg}$ had no effect on any of the measured parameters. The higher doses caused dose-dependent hemodynamic changes. Nifedipine $(50 \mu \mathrm{g} / \mathrm{kg})$, caused a significant fall in cardiac index associated with a marked decreased in left ventricular $\mathrm{dp} / \mathrm{dt}(p$ $<0.05$, Fig. 1). These changes were maximal approximately 30 $\mathrm{s}$ after injection and subsided by $10 \mathrm{~min}$. Heart rate increased while systemic arterial pressure and calculated resistance fell significantly $(p<0.05)$ (Fig. 3).

Nifedipine caused a small increase in pulmonary artery, right pulmonary vein, and left atrial pressures. These increases developed in parallel and no pressure gradient occurred between the pulmonary vein and the left atrium (Fig. 2). Calculated pulmonary arteriolar resistance in the injected lung increased significantly (Fig. $4, p<0.05$ ) and there was a maximal shift of $14 \pm$ $0.5 \%$ in flow away from the injected lung.

When Nifedipine $(50 \mu \mathrm{g} / \mathrm{kg})$ was injected as a bolus directly into the aortic root in three animals it caused systemic blood pressure and resistance to fall while heart rate increased and left ventricular $\mathrm{dp} / \mathrm{dt}$ showed little change.

Nifedipine and the response to hypoxia. Hypoxia caused pulmonary arteriolar resistance to increase significantly $(p<0.05)$ with a small increase in heart rate and left ventricular $\mathrm{dp} / \mathrm{dt}$. Aortic pressure and cardiac index remained unchanged. Table 1 shows the percentage changes $15 \mathrm{~min}$ after the onset of hypoxia 
in animals pretreated with Nifedipine and in age-matched controls. In the treated animals hypoxia was induced $30 \mathrm{~min}$ after a $50 \mu \mathrm{g} / \mathrm{kg}$ dose of Nifedipine; this was the final dose of a sequence of $2.5,25$, and 50 for a total of $77.5 \mu \mathrm{g} / \mathrm{kg}$. Nifedipine failed to alter the response to hypoxia.

In three separate experiments a bolus injection of Nifedipine $(50 \mu \mathrm{g} / \mathrm{kg})$ was given $15 \mathrm{~min}$ after the onset of hypoxia and caused a small further rise in pulmonary artery pressure with a marked fall in left ventricular $\mathrm{dp} / \mathrm{dt}$ and systemic vascular response.

Nifedipine infusions. Nifedipine $(50 \mu \mathrm{g} / \mathrm{kg})$ infused for $5 \mathrm{~min}$ into the pulmonary artery of three lambs for $5 \mathrm{~min}$ produced the same general effects as bolus injections. Pulmonary artery pressure and arteriolar resistance rose while cardiac index, aortic pressure, and systemic resistance fell. Cardiac contractility decreased and left atrial pressure rose. Heart rate also increased (Table 2).

\section{DISCUSSION}

Studies of drug action on the pulmonary vasculature in intact animals, create problems of interpretation because neither perfusion pressure nor flow can be controlled. Large increases in flow with little change in pressure result in marked decreases in calculated vascular resistance. This apparent "vasodilation" may be entirely passive due to distension of the highly compliant pulmonary vessels and/or recruitment of previously collapsed vessels. On the other hand, large pressure increases with little change in flow increase calculated resistance but because the increased perfusion pressure may open up hitherto collapsed vessels the true rise in active tone may actually be greater than the calculated resistance would suggest. A further potential error also arises because under conditions in which lung parenchymal pressure exceeds left atrial pressure the true resistance should be calculated using the parenchymal pressure to represent the down-

Table 1. Response to hypoxia (\% change) in Nifedipine pretreated lambs $(77.5 \mu \mathrm{g} / \mathrm{kg})$ and age-matched controls $(n=5$ in each group) $\pm 1 S E M^{*}$

\begin{tabular}{lcc}
\hline & Control & Nifedipine \\
\hline Pulmonary artery pressure & $+35 \pm 11$ & $+30 \pm 9$ \\
Pulmonary arteriolar resistance & $+70 \pm 11$ & $+72 \pm 12$ \\
Heart rate & $+9 \pm 5$ & $+9 \pm 2$ \\
Aortic mean pressure & $-3 \pm 3$ & $-5 \pm 1$ \\
Cardiac index & $+2 \pm 3$ & $+0.2 \pm 1$ \\
LV dp/dt & $+21 \pm 12$ & $+20 \pm 7$ \\
\hline
\end{tabular}

* The changes reported are $15 \mathrm{~min}$ after the onset of hypoxia. Hypoxia was tested $30 \mathrm{~min}$ after the last dose of Nifedipine.

Table 2. Effects of a 5-minute infusion of Nifedipine $50 \mu \mathrm{g} / \mathrm{kg}$ $\min (n=3) \pm S E M$

\begin{tabular}{|c|c|c|c|}
\hline & Baseline & $2 \mathrm{~min}$ & $5 \mathrm{~min}$ \\
\hline $\begin{array}{l}\text { Pulmonary artery pressure } \\
(\mathrm{mm} / \mathrm{Hg})\end{array}$ & $23 \pm 2.5$ & $28 \pm 1.7^{*}$ & $2.7^{*}$ \\
\hline $\begin{array}{l}\text { Aortic mean pressure ( } \mathrm{mm} / \\
\mathrm{Hg} \text { ) }\end{array}$ & $87 \pm 11$ & $64 \pm 6$ & $58 \pm 9^{*}$ \\
\hline $\begin{array}{l}\text { Left atrial mean pressure } \\
\qquad(\mathrm{mm} / \mathrm{Hg})\end{array}$ & $3 \pm 0.6$ & $6 \pm 0.6$ & $6 \pm 0.6$ \\
\hline Cardiac index $(\mathrm{ml} / \mathrm{min} / \mathrm{kg})$ & $239=$ & $223 \pm$ & $211 \pm 23$ \\
\hline Heart rate & $185=$ & 247 & 253 \\
\hline $\begin{array}{l}\text { Left ventricular } \mathrm{dp} / \mathrm{dt} \\
(\mathrm{mm} / \mathrm{Hg} / \mathrm{s})\end{array}$ & $3750 \pm 527$ & $2683 \pm 394$ & $2567 \pm 410$ \\
\hline $\begin{array}{l}\text { Pulmonary arteriolar resist- } \\
\text { ance }(\mathrm{U} / \mathrm{kg})\end{array}$ & $131 \pm 27$ & $176 \pm 40$ & $171 \pm 51$ \\
\hline Systemic resistance $(\mathrm{U} / \mathrm{kg})$ & $363 \pm 59$ & $284 \pm 40$ & $266 \pm 60$ \\
\hline
\end{tabular}

${ }^{*} p<0.05$, all other changes do not achieve statistical significance. stream pressure (6). Active vasodilatation can only be assumed to have occurred when pressure falls with either no change or an increase in flow.

There are several published reports of the pulmonary and systemic vascular effects of Nifedipine in experimental animals. In anesthetized adult dogs, Nifedipine $\left(10^{-6} \mathrm{M} / \mathrm{kg}\right)$ given intravenously over 2 min increased cardiac output while mean systemic pressure and calculated resistance fell (7). These authors also found that during normoxia, Nifedipine had no effect on pulmonary vascular resistance while it attenuated vasoconstriction induced by hypoxia or an infusion of prostaglandin $F_{2 \alpha}$. This "fall" in pulmonary resistance can be explained by the large increase in cardiac output and does not necessarily indicate active vasodilatation. Bishop and Cheney (8) also reported that Nifedipine increased cardiac output and pulmonary artery pressure with little change in calculated resistance. Hypoxic pulmonary vasoconstriction was attenuated. In contrast, in anesthetized dogs, Verapamil and Bepridil increased pulmonary vascular resistance and pressure, largely, but not entirely due to a sympathetic reflex (9). Hypertensive responses to Verapamil and $\mathrm{Be}$ pridil were also observed in isolated perfused guinea pig lungs (9). Nifedipine $(2.9 \mu \mathrm{M})$ inhibits potassium-induced contractions in isolated human pulmonary vessels by $87 \pm 2.8 \%$ (10). In anesthetized 5-day-old lambs, Nifedipine $50 \mu \mathrm{g} / \mathrm{kg}$ given as a bolus, caused pulmonary vasodilatation during hypoxia, but not normoxia. Cardiac output changes were not given (11).

Dickstein et al. (12) studied the effect of Nifedipine $(100 \mu \mathrm{g} /$ $\mathrm{kg}$ ) on hypoxia-induced pulmonary hypertension in mechanically ventilated anesthetized piglets. Pulmonary artery pressure fell significantly as did pulmonary arteriolar resistance. Cardiac output remained unchanged and systemic pressure fell profoundly and progressively. No significant change in pulmonary artery pressure was observed with a $10 \mu \mathrm{g} / \mathrm{kg}$ dose. The actions were generally transient except for the systemic hypotension associated with the higher dose. While these results are in accord with our own in regard to the systemic effects, the pulmonary vascular response is clearly different. This may reflect a true species difference or the possibility that these hypoxic anesthetized animals had much greater baseline cardiac depression. Left ventricular and diastolic pressure is not reported, but if it was elevated prior to administration of Nifedipine, it would probably fall in response to the marked systemic vasodilatation thereby causing a secondary fall in pulmonary artery pressure. Nifedipine's effect during normoxia was not tested.

Studies by Redding et al. (13) are most clearly allied to ours but with different results. In conscious piglets, age $10 \pm 3$ days they found that Nifedipine infused in a dose of $40 \mu \mathrm{g} / \mathrm{kg} / \mathrm{min}$ increased heart rate and reduced systemic pressure. Pulmonary artery pressure increased but unlike our lambs the piglets had a significant rise in cardiac output. Systemic resistance fell but pulmonary vascular resistance remained unchanged. During hypoxia, Nifedipine reduced the elevation in pulmonary vascular resistance by $45-99 \%$ in a dose-dependent manner. This effect was largely due to a Nifedipine-induced increase in cardiac output.

Based on these and many other studies there seems little doubt that Nifedipine causes systemic vasodilatation and increased heart rate. Its pulmonary vascular effects are less clear but we believe that our data show conclusively that Nifedipine has a "paradoxical" constrictor action in the pulmonary circulation of the conscious newborn lamb. The rise in pressure coupled with the fall in flow is strong presumptive evidence of active vasoconstriction which is further supported by the immediate shift in flow distribution away from the injected toward the contralateral lung.

Recent studies on the mechanism of action of the dihydropyridine derivatives suggests they may have both agonist and antagonist actions on calcium channels. Hess et al. (14) have proposed that the calcium channels may exist in three functional states, namely, channel unavailable (mode 0 ), brief openings (mode 1 ), 
and maintained openings with brief closings (mode 2). Dihydropyridines would act not by plugging the pore but by favoring one or other of the modes of gating. The same workers present evidence for a mixed action of Nitrendipine, which is closely related structurally to Nifedipine. Nifedipine has also been shown to increase cardiac contractility in low doses in contrast to its usual action. Thus there is evidence which supports the possibility that Nifedipine could act as a calcium agonist on the pulmonary vascular bed. This difference may be dose-related or due to more subtle changes in local conditions which alter the direction of effect in pulmonary as opposed to systemic smooth muscle.

Based on studies in adult animals Nifedipine is considered to have relatively less inotropic and chronotropic effects than Verapamil or Diltiazem; its direct cardiodepressant action being largely counteracted by its peripheral vasodilator action (4). In our newborn lambs, bolus injections of Nifedipine $(50 \mu \mathrm{g} / \mathrm{kg})$ caused marked falls in both cardiac index and left ventricular contractility suggesting a moderately severe cardiodepressant action. This marked sensitivity of the heart to Nifedipine accords with the effects in blood perfused isolated rabbit hearts reported by Boucek et al. (15) in which immature hearts were more sensitive to calcium blockade. The doses required to produce comparable reductions in developed pressure and $\mathrm{dp} / \mathrm{dt}$ were approximately 10 -fold less in immature compared with adult hearts.

Nifedipine is light sensitive and normally given orally or sublingually in man. More stable analogs which are light stable have the potential for parenteral administration. Given orally or sublingually, Nifedipine reaches a peak serum concentration in $1-2 \mathrm{~h}$ and persists for $8-12 \mathrm{~h}$. Intravenous Nifedipine $(15 \mu \mathrm{g} / \mathrm{kg})$ has approximately the same concentration time curve as $150 \mu \mathrm{g} /$ $\mathrm{kg}$ by the oral route (4). Despite this relatively long half-life the hemodynamic effects of Nifedipine are quite transient and subside fully within 8 min after a bolus injection and within $25 \mathrm{~min}$ of a 5 -min infusion of $50 \mu \mathrm{g} / \mathrm{kg} / \mathrm{min}$.

This transient effect was also observed by Dickstein et al. (12) and suggests that either the hemodynamic responses are nonspecific or that the action on calcium transport (whether agonist in the pulmonary circulation or channel blockade in the heart and systemic vessels) is quickly reversed by other factors.

There have been several reports of the clinical use of calcium channel blockers in adults with primary pulmonary hypertension, some suggesting benefit (1-3) and some, generally adverse effects $(16,17)$. In those papers which report specifically on the use of Nifedipine, the main action has been to increase cardiac output and evidence of true active pulmonary vasodilatation is lacking.
Assuming that there are no major species differences in response to Nifedipine our results indicate that there is little role for this drug in the management of pulmonary vasoconstrictive problems of the newborn.

Acknowledgments. The authors are grateful for the invaluable help of Mr. Frank Hamilton and for that of the word processing staff who typed the manuscript. Nifedipine was generously donated by David Frankel Ph.D., Miles Laboratories, Rexdale, Ontario, Canada.

\section{REFERENCES}

1. Camerini F, Alberti E, Klugmann S, Salvi A 1980 Primary pulmonary hypertension: effects of nifedipine. Br Heart J 44:352-356

2. Fisher J, Borer JS, Moses JW, Goldberg HL, Niarchos AP, Whitman HH, Mermelstein M 1984 Hemodynamic effects of nifedipine versus hydralazine in primary pulmonary hypertension. Am J Cardiol 54:646-650

3. Simonneau G, Escourrou P, Duroux P, Lockhart A 1981 Inhibition of hypoxic pulmonary vasoconstriction by Nifedipine. N Engl J Med 304:1582-1585

4. Saini RK 1984 Calcium antagonists. In: Antonaccio M (ed) Cardiovascular Pharmacology, 2nd ed. Raven Press, New York, pp 415-452

5. Lock JE, Hamilton F, Luide H, Coceani F, Olley PM 1980 Direct pulmonary vascular responses in conscious newborn lambs. J Appl Physiol 48:188-196

6. Sniderman A, McGregor M 1985 On pulmonary vascular resistance: the need for more precise definition. Am J Cardiol 55:217-221

7. Young TE, Lundquist LJ, Chesler E, Weir EK 1983 Comparative effects of Nifedipine, Verapamil, and Diltiazem on experiental pulmonary hypertension. Am J Cardiol 51:195-200

8. Bishop MJ, Cheney FW 1983 Comparison of the effects of Minoxidil and Nifedipine on hypoxic pulmonary vasoconstriction in dogs. J Cardiovasc Pharmacol 5:184-189.

9. Barrett AM, Frankish NH, Yates MS 1981 The effects of calcium antagonists on pulmonary hemodynamics. Br J Pharmacol 74:946P-947P

10. Sakr AM, Mikkelsen E 1983 Effects of Nifedipine on isolated human pulmonary vessels. Gen Pharmacol 14:115-116

11. Philips JB, Lyrene RK, Leslie GI, McDevitt M, Cassady G 1982 Cardiopulmonary effects of Nifedipine in normoxic and hypoxic newborn lambs. Circulation 66:II-III(abstr)

12. Dickstein PJ, Trindade O, Goldberg RN, Bancalari E 1984 The effect of calcium antagonists on hypoxic pulmonary hypertension in the piglet. Pediatr Res 18:1262-1265

13. Redding GH, Tuck R, Escourrou P 1984 Nifedipine attenuates acute hypoxic pulmonary vasoconstriction in awake piglets. Am Rev Respir Dis 129:785789

14. Hess P, Lansman JB, Tsien RW 1984 Different modes of Ca channel gating behavior favoured by dihydropyridine $\mathrm{Ca}$ agonists and antagonists. Nature 311:538-544

15. Boucek RJ, Shelton M, Artman M, Mushlin PS, Starnes VA, Olson RD 1984 Comparative effects of Verapamil, Nifedipine, and Diltiazem on contractile function in the isolated immature and adult rabbit heart. Pediatr Res 18:948952

16. Landmark K, Refsum AM, Simonsen S, Storstein 1978 Verapamil and pulmonary hypertension. Acta Med Scand 204:299-302

17. Packer M, Medina N, Yushak M, Wienar I 1984 Detrimental effects of Verapamil in patients with primary pulmonary hypertension. Br Heart $\mathrm{J}$ $52: 106-11$ 